RUNNING HEAD: INTERRUPTIONS BY PAIN: REVIEW AND MODEL

Interrupted by pain: An anatomy of pain-contingent activity interruptions

Keywords: (chronic) pain; task interruption; task performance; activity pattern; goal pursuit

Rena Gatzounis $^{\mathrm{a}, \mathrm{b}^{*}}$, MSc, Martien G.S. Schrooten ${ }^{\mathrm{a}, \mathrm{c}}, \mathrm{PhD}$, Geert Crombez ${ }^{\mathrm{d}}, \mathrm{PhD}$, and Johan W.S. Vlaeyen ${ }^{\mathrm{a}, \mathrm{b}}, \mathrm{PhD}$

${ }^{a}$ Research Group Health Psychology, University of Leuven, Belgium

${ }^{\mathrm{b}}$ Department of Clinical Psychological Science, Maastricht University, Maastricht, The Netherlands

${ }^{c}$ Centre for Health and Medical Psychology, Örebro University, Örebro, Sweden

${ }^{\mathrm{d}}$ Department of Experimental-Clinical and Health Psychology, Ghent University, Ghent, Belgium

*Address correspondence to:

Rena Gatzounis

Research Group Health Psychology, University of Leuven

Tiensestraat 102, box 3726

B-3000 Leuven, Belgium

Phone number: +32 163 73040; Fax number: +32 16326144

E-mail address: Rena.Gatzounis@ppw.kuleuven.be

URL: http://ppw.kuleuven.be/home/english/research/ogp/RenaGatzounis

[text pages: 14 (including title page and references); word count: 2089; figures: 1] 


\section{Interrupted by pain: An anatomy of pain-contingent activity interruptions}

\section{Introduction}

According to the Oxford Dictionary, interruptions occur when the continuous progress of an activity or process is halted [20]. Pain is an interrupting stimulus, as it often disturbs the course or continuation of ongoing processes or activities, and usually results in their temporary suspension. Over 10 years ago, Eccleston and Crombez [14] called for a focus on the interruptive function of pain, arguing that pain "interrupts attention, ruptures behavior, and imposes a new action priority to escape" [p. 356]. Although there is now abundant research on the interruptive function of pain [14], it has largely focused on short-lived impairments of attention and task performance whilst experiencing or anticipating pain [e.g. 30,35]. A different situation occurs when activities are suspended for longer time intervals before being resumed [28]. Situations in which unfinished activities are suspended and postponed because of pain, but with the intention to be resumed later have been far less investigated [29] and require further theoretical analysis.

In this manuscript we discuss the potential consequences of interruptions for behaviour and goal pursuit, and highlight the effects of interruption characteristics on subsequent performance and behaviour. Further, we synthesize relevant empirical findings from within and outside the pain field to introduce a model for pain-contingent interruptions. Finally, we discuss clinical and research implications.

\section{Interruptions by pain}

Interrupting an ongoing activity in response to pain allows one to turn to the pain and its cause and to engage in protective actions [14]. People in pain may experience a conflict between either interrupting an activity to ease, escape or avoid pain, or continuing the activity and approaching valuable non-pain goals $[10,36]$. Goal conflicts have a negative impact on 
affect and well-being [21,27] and may lead to symptom exacerbation [17]. A possible resolution of the conflict is to temporarily suspend non-pain-related activities. Repeated and persistent activity suspensions have indeed been observed in chronic pain patients [14], who seem to exhibit a less stable activity pattern than healthy individuals [39]. Such activity fluctuations contribute to disability [19].

Although interruptions offer the opportunity for momentary pain relief, they can also hamper the pursuit and achievement of valued goals, with detrimental consequences for functioning, identity, life satisfaction, and affect [9,24]. Indeed, the frequent attempts of chronic pain patients to regulate and schedule their breaks, rather than taking them in response to pain $[16,25,26]$, suggest that pain-contingent interruptions can be experienced as disruptive. This may especially be the case when pain is perceived as threatening. A recent experiment demonstrated that healthy volunteers high in pain catastrophizing tended to spend less time on a cognitive task after being interrupted by pain compared to when they were allowed to work uninterrupted. Low catastrophizers exhibited the reverse behavioural pattern [29].

Unfortunately, further knowledge on the consequences of pain-contingent interruptions for subsequent task performance, goal pursuit, cognition and affect is lacking. Research from outside the pain field can generate interesting predictions.

\section{Interruption research outside the pain field}

Task interruptions have been investigated in other areas, especially in human factors and ergonomics [34]. In the typical experimental paradigm used to examine task interruptions outside the pain field, participants engage in a (cognitive) task before being interrupted by a second activity. After some time on the interrupting activity, they can return to the interrupted task. Typical measurements include the probability that the interrupted task will be resumed, the time it takes to resume, and performance indices after resumption [e.g. 23]. This literature 
shows that, although in some occasions interruptions facilitate task performance [31], their behavioural, cognitive, motivational and affective consequences are most often detrimental $[1,5,6,34]$. Importantly, these consequences may vary depending on the interruption characteristics [5,34]. Experimental research has shown, for example, that interruptions of long duration are more disruptive than short ones [23]. Also, timing is important [1]: interruptions occurring right before task completion affect executive functioning, presumably because the urge to complete the goal increases as its attainment nears [15]. Moreover, expected interruptions are less disruptive and experienced as less stressful than unexpected ones [8], possibly because they offer the opportunity to prepare, for example by creating reminders that can be used to resume the activity later. Environmental cues can indeed facilitate subsequent activity resumption [32]. Further, there are indications that the more frequently interruptions occur, the easier it becomes to adapt to and regulate them [33].

Findings from outside the pain field, however, may not necessarily apply to pain. Pain is an internal event with typical characteristics (e.g. threatening, unpleasant, often unpredictable) that may render pain-contingent interruptions different from non-pain interruptions. Nevertheless, this research provides a starting point. We adopt the perspective that interruption effects depend on interruption characteristics and, in the next section, we synthesize findings from within and outside the pain field to propose an "anatomy" of paincontingent activity interruptions.

\section{An anatomy of pain-contingent interruptions}

Building upon models from outside the pain field [2,5,6,34], figure 1 outlines the expected sequence of events occurring when a person's ongoing activity is interrupted by pain. The stages are as follows. 
1. Pursuit non-pain Goal A. The person is performing a physical or cognitive activity in service of a valuable non-pain goal.

2. Interruption cue: Pain. Pain captures attention and urges the person to suspend the ongoing activity and engage in protective actions [14]. The degree to which pain or signals of impending pain capture attention and are evaluated as requiring immediate action is influenced by various factors [11,37]. For example, pursuing a highly valued goal has been found to lower the attentional demand of pain [30]. The extent of attentional capture may affect the probability of task suspension and the quality of performance after task resumption.

3. Interruption lag. After the interruption cue, the person may first try to "wrap up" an activity before suspending it. The interruption lag is the interval between interruption cue onset and disengagement from the interrupted task [cf. 33,34]. It is considered important for resuming the interrupted activity later [2] because it provides the opportunity to encode the intention to resume the activity and task-related information into prospective memory [13], which is the memory for actions to be performed in the future [12].

Variations in length of the interruption lag are associated with different consequences, with longer interruption lags facilitating activity resumption [33]. Pain may cause one to interrupt activities reflexively, especially persons who are fearful of pain [40]. Such abrupt responses may limit the interruption lag duration dramatically, leaving virtually no opportunity to encode in memory the intention to resume the activity and/or information about the state of the activity, thus possibly impairing activity resumption [13].

4. Pursuit pain-relief Goal B. As pain relief becomes a salient goal, the person disengages from the interrupted activity. Pain is escaped from or controlled by means of, e.g. distraction 
techniques, protective behaviours, or simply taking some rest. Various factors at this stage may influence the subsequent resumption of the interrupted activity. For instance, the longer one stays disengaged from the interrupted task, the more task-relevant information may decay from memory $[18,23]$. This might be especially detrimental for cognitive tasks, such as when one takes a break from writing a manuscript in order to walk around and relieve back pain. Moreover, having to take long breaks from valued activities, e.g. playing with one's children, may increase negative affect.

5. Cue termination pain-relief Goal B. Goal B pursuit lasts at least until a cue signals that the interrupted activity can or should be resumed. Examples of such cues are the decrease of pain intensity to an acceptably lower level, or an approaching deadline for task completion. Internal cues such as pain relief may be too subtle to be perceived immediately at the exact time they occur, possibly leading to prolongation of the interruption. Alternatively, the person may resume the interrupted task despite pain, if, for example, the task aims at the fulfillment of a valued goal. External or situational cues (e.g., alarm clocks) are explicit reminders that may increase the probability of activity resumption [13].

6. Resumption lag. The resumption lag is the interval between the disengagement from goal B-related activity and the resumption of goal A-related activity, and is influenced by at least two processes [33]. The first relates to task switching costs [33], i.e. the typical finding that performance is impaired when one switches from one activity to another, compared to continuing with the same activity. In the field of pain it has been shown that switching from a painful task to another activity imposes higher costs than switching from a non-painful task to another activity [38]. The second process involves retrieving from memory the information regarding the interrupted task [33]. Retrieval depends on how well this information had been 
encoded to memory during the interruption lag [33], characteristics of goal B-related activity, but also on conditions during the resumption lag, such as the presence of reminders indicating where the activity should be resumed from [32]. The duration of the resumption lag has been shown to influence quality of performance after resumption, with longer resumption lags decreasing the probability of errors [7]. Facing difficulties with retrieval, however, may decrease the probability to resume the task.

7. Resumption non-pain Goal A. Interruption, goal, pain and personal characteristics (e.g. perceived threat value of pain [29]) interact to determine whether and how successfully the interrupted activity is resumed. Impaired performance after resumption may lead to negative affect. The person may adopt compensatory strategies (e.g., perform the task faster), which may prevent performance decrements but cause more stress and frustration [22]. Moreover, the person may not necessarily act upon the initial intention to resume the interrupted activity, for instance because the opportunity to resume the task has passed, or because alternative paths to achieve goal A exist (e.g., another person is willing to resume and complete the interrupted activity). Thus, investigating various outcomes (e.g., probability and ability to resume the task, affective variables, pain perception) will help us better understand the processes that operate during the interruption.

\section{Implications}

Interrupting ongoing tasks because of pain is expected to have a negative impact on everyday activities and pursuit of valued goals. Various factors, however, might render interruptions less debilitating. For example, people might be more likely to resume an interrupted activity when an explicit cue (e.g. alarm clock) indicates that it is time to do so, and they might perform better after resumption if they have been interrupted for a short time. Knowledge of 
these factors is of theoretical value, as it can foster our understanding of the impact of pain on daily functioning.

Moreover, the identification of these factors has potential clinical implications, as it could be applied on pain interventions requiring task interruptions, such as activity pacing. As a technique learned in the context of cognitive-behavioural treatment, activity pacing involves taking breaks that are regular, prescheduled, and contingent on cues other than pain [26]. Pacing is expected to help patients manage their activity level by breaking the dysfunctional pattern of extreme activity level fluctuations [25,26]. Whether pacing is indeed helpful, though, remains unclear [16]. A recent meta-analysis found weak correlations with pain and physical disability, but also with better psychological functioning [3]. This meta-analysis, however, included studies in which breaks may have also been pain-contingent. The effects of pacing as a technique learned in pain management programs have not been systematically examined, and when they have, the breaks employed have not been adequately described $[16,25]$. In order to better understand the effects and mechanisms of activity pacing, interruption characteristics, such as the type of interruption cue, must be considered. For example, breaks signaled by an external, non-pain cue, such as time (time-contingent breaks) or the completion of sub-goals of the activity (goal-contingent breaks) may be less disruptive than pain-contingent breaks. Scheduled, predictable breaks may offer the opportunity to control the length of the interruption lag and prepare for resumption [33], and external cues (such as alarm clocks [4]) may increase the probability of activity resumption [13].

Identifying factors that influence the consequences of interruptions will point to ways to mitigate their expected negative effects. Hence, experimental research, which allows the manipulation of interruption characteristics, is needed. Our working model may serve as a theoretical basis for such research. 


\section{Conclusions}

Although activity interruptions occur often in the context of pain, their effects on subsequent task resumption have been scarcely studied. In this paper we highlighted the relevance of considering interruption characteristics, and reviewed existing evidence in the context of a working model of pain-contingent interruptions. This theoretical framework may accommodate future research on pain-related activity interruptions.

\section{Acknowledgements}

This work was supported by the Research Foundation - Flanders, Belgium (FWO Vlaanderen). The authors declare no conflict of interest.

\section{References}

[1] Adamczyk PD, Bailey BP. If not now, when? The effects of interruption at different moments within task execution. In: Dykstra-Erickson E, Tscheligi M, editors. Proceedings of the SIGCHI Conference on Human Factors in Computing Systems; 2004 Apr 24-29; Vienna, Austria. New York: ACM Press; 2004. p. 1-8.

[2] Altmann EM, Trafton JG. Memory for goals. An activation-based model. Cogn Sci 2002;26:39-83.

[3] Andrews NE, Strong J, Meredith PJ. Activity pacing, avoidance, endurance and associations with patient functioning in chronic pain. A systematic review and metaanalysis. Arch Phys Med Rehabil 2012;93:2109-2121.e7.

[4] Birkholtz M, Aylwin L, Harman RM. Activity pacing in chronic pain management. One aim, but which method? Part two: national activity pacing survey. Br J Occup Ther 2004;67:481-487.

[5] Boehm-Davis DA, Remington R. Reducing the disruptive effects of interruption. A 
cognitive framework for analyzing the costs and benefits of intervention strategies. Accid Anal Prev 2009;41:1124-1129.

[6] Brixey JJ, Robinson DJ, Johnson CW, Johnson TR, Turley JP, Zhang J. A concept analysis of the phenomenon interruption. ANS Adv Nurs Sci 2007;30:E26-E42.

[7] Brumby DP, Cox AL, Back J, Gould SJJ. Recovering from an interruption. Investigating speed-accuracy trade-offs in task resumption behavior. J Exp Psychol Appl 2013;19:95-107.

[8] Carton AM, Aiello JR. (2009). Control and anticipation of social interruptions. Reduced stress and improved task performance. J Appl Soc Psychol 2009;39:169-185.

[9] Carver CS, Scheier MF. Origins and functions of positive and negative affect. A control-process view. Psychol Rev 1990;97:19-35.

[10] Crombez G, Eccleston C, Van Damme S, Vlaeyen JWS, Karoly P. Fear-avoidance model of chronic pain. The next generation. Clin J Pain 2012;28:475-483.

[11] Crombez G, Van Ryckeghem DML, Eccleston C, Van Damme S. Attentional bias to pain-related information. A meta-analysis. Pain 2013; 154:497-510.

[12] Dismukes RK. Remembrance of things future. Prospective memory in laboratory, workplace, and everyday settings. Rev Hum Factors Ergon 2010;6:79-122.

[13] Dodhia RM, Dismukes RK. Interruptions create prospective memory tasks. Appl Cogn Psychol 2009;23:73-89.

[14] Eccleston C, Crombez G. Pain demands attention. A cognitive-affective model of the interruptive function of pain. Psychol Bull 1999;125:356-366.

[15] Freeman N, Muraven M. Don't interrupt me! Task interruption depleted the self's limited resources. Motiv Emot 2010;34:230-241.

[16] Gill JR, Brown CA. A structured review of the evidence for pacing as a chronic pain intervention. Eur J Pain 2009;13:214-216. 
[17] Hardy JK, Crofford LJ, Segerstrom SC. Goal conflict, distress, and pain in women with fibromyalgia. A daily diary study. J Psychosom Res 2011;70:534-540.

[18] Hodgetts HM, Jones DM. Interruption of the Tower of London task. Support for a goal-activation approach. J Exp Psychol-Gen 2006;135:103-115.

[19] Huijnen IPJ, Verbunt JA, Roelofs J, Goossens M, Peters M. The disabling role of fluctuations in physical activity in patients with chronic low back pain. Eur J Pain 2009;13:1076-1079.

[20] Interrupt. In: Oxforddictionaries.com [Internet]. Oxford: University Press [retrieved and cited 2012 Dec 29]. Available from http://oxforddictionaries.com/definition/english/interrupt?q=interrupt.

[21] Karoly P, Okun MA, Ruelhman LS, Pugliese JA. The impact of goal cognition and pain severity on disability and depression in adults with chronic pain. An examination of direct effects and mediated effects via pain-induced fear. Cognit Ther Res $2008 ; 32: 418-433$.

[22] Mark G, Gudith D, Klocke U. The cost of interrupted work. More speed and stress. In: Czerwinski M, Lund A, Tan D, editors. Proceedings of the SIGCHI Conference on Human Factors in Computing Systems; 2008 Apr 5-10; Florence, Italy. New York: ACM Press; 2008. p. 107-110.

[23] Monk CA, Trafton JG, Boehm-Davis DA. The effect of interruption duration and demand on resuming suspended goals. J Exp Psychol-Appl 2008;14:299-313.

[24] Morley S. Psychology of pain. Br J Anaesth 2008;101:25-31.

[25] Nielson WR, Jensen MP, Karsdorp PA, Vlaeyen JWS. Activity pacing in chronic pain. Concepts, evidence and future directions. Clin J Pain 2013;29:461-468.

[26] Otis JD. Managing chronic pain. A cognitive-behavioral therapy approach. Oxford: University Press, 2007. 
[27] Riediger M, Freund AM. Interference and facilitation among personal goals. Differential associations with subjective well-being and persistent goal pursuit. Pers Soc Psychol Bull 2004;30:1511-1523.

[28] Salvucci DD, Taatgen NA, Borst JP. Toward a unifying theory of the multitasking continuum. From concurrent performance to task switching, interruption, and resumption. In: Greenberg S, Hudson SE, Hinckley K, Morris MR, Olsen DR, editors. Proceedings of the SIGCHI Conference on Human Factors in Computing Systems; 2009 Apr 4-9; Boston, MA, USA. New York: ACM Press; 2009. p. 1819-1828.

[29] Schrooten MGS, Karsdorp PA, Vlaeyen JWS. Pain catastrophizing moderates the effects of pain-contingent task interruptions. Eur J Pain 2013;17:1082-1092.

[30] Schrooten MGS, Van Damme S, Crombez G, Peters ML, Vogt J, Vlaeyen JWS. Nonpain goal pursuit inhibits attentional bias to pain. Pain 2012;153:1180-1186.

[31] Speier C, Valacich JS, Vessey I. The influence of task interruption on individual decision making, An information overload perspective. Decision Sci 1999;30:337-360.

[32] Trafton JG, Altmann EM, Brock DP. Huh, what was I doing? How people use environmental cues after an interruption. In: Proceedings of the Human Factors and Ergonomics Society 49th Annual Meeting; 2005 Sep 26-30; Orlando, FL, USA. Santa Monica, CA: Human Factors and Ergonomics Society; 2005. p. 468-472.

[33] Trafton JG, Altmann EM, Brock DP, Mintz FE. Preparing to resume an interrupted task. Effects of prospective goal encoding and retrospective rehearsal. Int J Hum Comput Stud 2003;58:583-603.

[34] Trafton JG, Monk CA. Task interruptions. Rev Hum Factors Ergon 2007;3:111-126.

[35] Vancleef LMG, Peters ML. Pain catastrophizing, but not injury/illness sensitivity or anxiety sensitivity, enhances attentional interference by pain. J Pain 2006;7:23-30.

[36] Van Damme S, Crombez G, Eccleston C. Coping with pain. A motivational 
perspective. Pain 2008;139:1-4.

[37] Van Damme S, Legrain V, Vogt J, Crombez G. Keeping pain in mind. A motivational account of attention to pain. Neurosci Biobehav Rev 2010;34:204-213.

[38] Van Ryckeghem DML, Crombez G, Eccleston C, Liefooghe B, Van Damme S. The interruptive effect of pain in a multitask environment. An experimental investigation. $\mathbf{J}$ Pain 2012;13:131-138.

[39] van Weering MGH, Vollenbroeck-Hutten MMR, Tönis TM, Hermens HJ. Daily physical activities in chronic lower back pain patients assessed with accelerometry. Eur J Pain 2009;13:649-654.

[40] Vlaeyen JWS, Linton SJ. Fear-avoidance model of chronic musculoskeletal pain. 12 years on. Pain 2012;153:1144-1147. 
Figure 1. An anatomy of pain-contingent activity interruptions.

The person is engaged in an activity in pursuit of a focal non-pain goal A (stage 1), when pain onset or increase captures attention and urges them to suspend the ongoing activity (stage 2). The interval between the interruption cue onset and the disengagement from the pursuit of goal A is the interruption lag (stage 3). During this interval, the intention to resume the pursuit of goal A, as well as task-relevant information are encoded into prospective memory. Subsequently, the person engages in the pursuit of a pain relief goal B (stage 4). A cue indicates when goal B pursuit can be terminated (stage 5). This is followed by the resumption lag, i.e. the interval during which the task-relevant information is retrieved from memory (stage 6) and, eventually, by the resumption of the interrupted activity (stage 7).

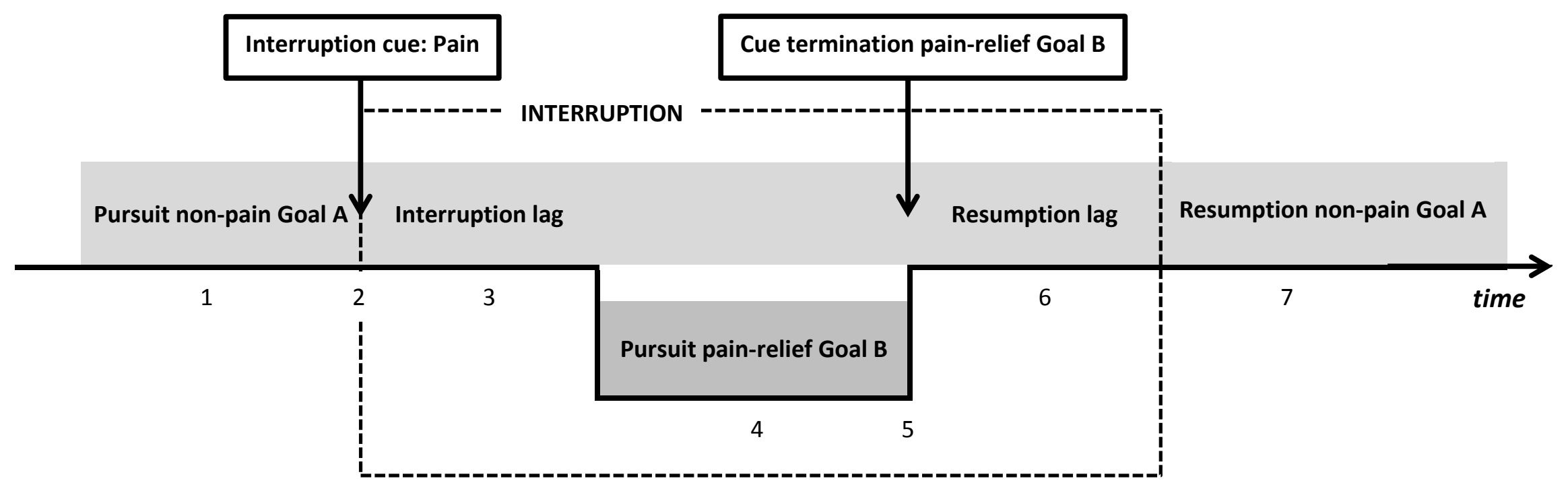

